\title{
Gender Difference in Symptom Presentations Among Patients With Bone Metastases in Gender-Specific and Gender-Neutral Primary Cancers
}

\author{
Shaelyn Culleton ${ }^{\mathrm{a}}$, Kristopher Dennis ${ }^{\mathrm{a}}$, Kaitlin Koo ${ }^{\mathrm{a}}$, Liying Zhang ${ }^{\mathrm{a}}$, Liang Zeng, \\ Janet Nguyen ${ }^{\text {a }}$ Florencia Jon ${ }^{\text {a }}$, Lori Holden ${ }^{\text {a }}$ Elizabeth Barnes ${ }^{\mathrm{a}}$, May Tsao, \\ Cyril Danjoux $^{\mathrm{a}}$, Arjun Sahgal ${ }^{\mathrm{a}}$, Edward Chow ${ }^{\mathrm{a}, \mathrm{b}}$
}

\begin{abstract}
Background: Studies have assessed gender differences on symptoms commonly experienced by cancer patients at various stages in their disease trajectory using heterogeneous cancer populations with different tumor types. The purpose of our study was to evaluate the effect of gender on symptoms among patients with bone metastases while controlling for gender-specific malignancies.
\end{abstract}

Methods: A retrospective review of patients receiving palliative radiotherapy for bone metastases was conducted on patients that completed the Brief Pain Inventory (BPI) or Edmonton Symptom Assessment System (ESAS) questionnaires from 1999 - 2004. Baseline and follow-up BPI and ESAS symptom scores were compared between males and females, with and without controlling for gender-specific tumors.

Results: A total of 900 patients completed baseline questionnaires: ESAS $(n=508)$ or BPI $(n=392)$. The most common tumor types were lung (26\%), breast $(25 \%)$ and prostate $(24 \%)$. In all ESAS patients, females had significantly greater severity of tiredness, nausea, depression, anxiety and breathlessness. In the subgroup analysis when gender-specific primary cancers were removed (i.e., breast, prostate and gynecological), no significant differences in ESAS symptoms were found between genders. The BPI functional

Manuscript accepted for publication April 8, 2011

${ }^{a}$ Rapid Response Radiotherapy Program, Department of Radiation Oncology, Odette Cancer Center, Sunnybrook Health Sciences Center, University of Toronto, Canada

${ }^{\mathrm{b}}$ Corresponding author: Edward Chow, Department of Radiation Oncology, Odette Cancer Center, Sunnybrook Health Sciences Center, 2075 Bayview Avenue, Toronto, ON M4N 3M5, Canada.

Email: Edward.Chow@sunnybrook.ca

doi:10.4021/wjon306w item of walking ability was significantly worse for females in both the overall and subgroup analyses. Females had worse symptoms at follow-up prior to the removal of gender-specific primaries in both ESAS and BPI.

Conclusions: Gender-specific cancers may significantly bias gender studies of cancer-related symptoms when primary tumor type is not taken into account. Gender differences are best assessed in gender-neutral primaries.

Keywords: Advanced cancer; BPI; ESAS; Gender difference; Symptoms

\section{Introduction}

Patients with advanced cancer often experience a variety of physical, functional and psychosocial symptoms in association with their disease, which in turn can have a significant impact on their quality of life (QoL) [1]. These patients are often reported to be 'polysymptomatic' with respect to their advanced cancer $[2,3]$. In addition to physical symptoms, the incidence of psychological disturbances has been estimated from $0-49 \%$ in the general cancer population, however significant levels of depression and anxiety have only been found to be around $19 \%$ and $24 \%$ respectively $[4,5]$. In an effort to correlate possible demographic and treatment-related variables to symptoms commonly associated with cancer, many of these studies have found that younger patients [1, 5-11], patients with poorer performance status [11-13] and females $[1,5,9-12,14,15]$ are more likely to experience psychological distress and/or symptoms of anxiety and depression. Female cancer patients have also been reported to experience more nausea and/or vomiting as well as more nociceptive pain when compared with male cancer patients $[2,3,10,11,16-18]$.

Most of the above studies used heterogeneous cancer populations that included various tumor types and disease stages. Specifically with respect to gender differences, many meta-analyses and studies with more uniform populations of cancer patients have found no concrete evidence in support 
of such reported gender related symptom differences $[6,19$ 24]. Very few studies have acknowledged the potential bias in including breast, prostate and gynecological cancer sites in correlational studies, particularly when they comment on gender related differences in the prevalence and severity of symptoms. Some authors have noted that gender-specific primary sites may influence the pattern and severity of symptoms and that these differences may be attributed to different hormone and chemotherapy treatments, the public's perception of specific cancers as well as different self-reporting styles between the sexes [1, 3, 10, 16, 25-27]. It has been suggested that in order to elucidate the true effect of gender on symptoms in the cancer population, future studies should evaluate the gender effect in patients with similar distributions of primary cancers or in patients with cancers that are not gender-specific $[1,28]$. Accordingly, the purpose of this study was to evaluate the effect that gender-specific primaries may have on commonly reported physical, functional and psychosocial symptoms in a population of advanced cancer patients with bone metastases.

\section{Methods}

\section{Patient population}

A retrospective analysis was conducted on data from patients who had participated in only one of two previous mutually exclusive prospective longitudinal studies that occurred between 1999 and 2004. One used the Edmonton Symptom Assessment System (ESAS) and the other used the Brief Pain Inventory (BPI). Both studies assessed patients at baseline and at post-treatment follow-up. Patients were to be assessed at follow-up at 1,2,4 weeks after the radiation treatment and then monthly afterwards, and we allowed a window phase of 1 week during these designated times of follow-up. Patients were accrued from an outpatient radiotherapy clinic that operated daily at the Sunnybrook Odette Cancer Center, Toronto, Ontario, Canada. Ethics approval was received for this study from the hospital's research ethics board. Patients considered for enrolment in the aforementioned studies had to have been over 18 years of age, had biopsy-proven cancer, spoke English, and received palliative radiotherapy (RT) for painful bone metastases.

\section{Edmonton Symptom Assessment System (ESAS)}

The ESAS is a validated 9-item patient-rated tool where symptoms are scored on an 11-point visual analogue scale where 0 is absence of a symptom and 10 is the worst possible feeling or experience of that symptom. The symptoms assessed by the ESAS are pain, tiredness, nausea, depression, anxiety, drowsiness, appetite loss, well-being and breathlessness. The tool was initially developed for the palliative care setting and is known for its brevity, reliability and ease of completion $[29,30]$.

\section{Brief Pain Inventory (BPI)}

The BPI is a validated inventory that assesses the severity and impact of pain. It asks patients to rate their current, average and worst pain on an 11-point visual analogue scale where 0 is 'no pain' and 10 is 'pain as bad as you can imagine'. Patients are also asked to rate how much pain interferes with their enjoyment of life, level of activity, ability to walk, mood, sleep, work and relations with others on a 11-point visual analogue scale where 0 is defined as 'does not interfere' and 10 is defined as 'completely interferes'. This tool has been utilized in patients with bone metastases and is known for its reliability and sensitivity [31].

\section{Statistical analysis}

Patients enrolled on both the ESAS and BPI studies who completed the ESAS and BPI were analysed in two separate groups: overall and subgroup patients. The overall analyses of the ESAS and BPI groups respectively were conducted in all patients including all primary cancer sites. The separate subgroup analyses excluding all gender-specific primaries (breast, prostate and gynecological cancers) were repeated. Demographic results were expressed as median and range for age and KPS; as proportions for primary cancer site in overall patients and in males and females, respectively. Because both ESAS and BPI score distributions were not normalized, Wilcoxon rank-sum non-parametric tests were used to compare males and females for each ESAS and BPI score at baseline and at each follow-up. A P-value of less than 0.05 was considered statistically significant. All analyses were conducted by Statistical Analysis Software (SAS version 9.2 for Windows).

\section{Results}

In total, 900 patients were included in the present analysis. Five hundred and eight had been previously enrolled on the ESAS study and 392 had been previously enrolled on the BPI study. During 2004 - 2009 (the period during which patients for the current analysis was enrolled to these studies), 3350 patients were referred to the outpatient clinic from which all patients were enrolled. During a typical year, $60 \%$ of all new referrals to the clinic are patients with painful bone metastases. Detailed information about patients not enrolled to studies is not retained.

\section{Edmonton Symptom Assessment System}

\section{All patients}


Table 1. Baseline ESAS Cohort Demographics

\begin{tabular}{|c|c|c|c|c|c|c|}
\hline & \multicolumn{3}{|c|}{ All Patients } & \multicolumn{3}{|c|}{ Sub-Analysis } \\
\hline & $\mathbf{M}$ & $\mathbf{F}$ & Overall & M & $\mathbf{F}$ & Overall \\
\hline $\mathrm{N}$ & 275 & 233 & 508 & 158 & 104 & 262 \\
\hline$\%$ & $54 \%$ & $46 \%$ & $100 \%$ & $60 \%$ & $40 \%$ & $100 \%$ \\
\hline \multicolumn{7}{|l|}{ Age } \\
\hline Median (years) & 71 & 67 & 69 & 67 & 69 & 68 \\
\hline Range & $37-94$ & $59-76$ & $32-94$ & $37-86$ & $32-89$ & $61-75$ \\
\hline \multicolumn{7}{|l|}{ KPS } \\
\hline Median & 60 & 60 & 60 & 60 & 60 & 60 \\
\hline Range & $10-90$ & $30-100$ & $10-100$ & $40-90$ & $30-90$ & $30-90$ \\
\hline \multicolumn{7}{|c|}{ Primary Cancer Site (N =; \%) } \\
\hline Lung & $78(28 \%)$ & $50(21 \%)$ & $128(25 \%)$ & $78(49 \%)$ & $50(48 \%)$ & $128(49 \%)$ \\
\hline Breast & --- & $125(54 \%)$ & $125(25 \%)$ & --- & --- & --- \\
\hline Prostate & $117(43 \%)$ & --- & $117(23 \%)$ & --- & --- & --- \\
\hline Unknown & $17(6 \%)$ & $16(7 \%)$ & $66(7 \%)$ & $17(11 \%)$ & $16(15 \%)$ & $33(13 \%)$ \\
\hline Multiple Myeloma & $15(5 \%)$ & $13(6 \%)$ & $28(6 \%)$ & $15(10 \%)$ & $13(13 \%)$ & $28(11 \%)$ \\
\hline Colorectal & $18(7 \%)$ & $9(4 \%)$ & $27(5 \%)$ & $18(11 \%)$ & $9(9 \%)$ & $27(10 \%)$ \\
\hline Renal Cell & $10(4 \%)$ & $5(2 \%)$ & $15(3 \%)$ & $10(7 \%)$ & $5(5 \%)$ & $15(6 \%)$ \\
\hline Other GI & $10(4 \%)$ & $1(1 \%)$ & $11(2 \%)$ & $10(7 \%)$ & $1(1 \%)$ & $11(4 \%)$ \\
\hline Bladder & $6(2 \%)$ & $3(1 \%)$ & $9(2 \%)$ & $6(4 \%)$ & $3(3 \%)$ & $9(3 \%)$ \\
\hline GYN & --- & $4(2 \%)$ & $4(1 \%)$ & --- & --- & --- \\
\hline Others & $4(1 \%)$ & $7(3 \%)$ & $11(2 \%)$ & $4(3 \%)$ & $7(7 \%)$ & $11(4 \%)$ \\
\hline \multicolumn{7}{|l|}{ Dose/Fraction $(\mathrm{N}=; \%)$} \\
\hline $800 / 1$ & $127(46 \%)$ & $91(39 \%)$ & $218(43 \%)$ & $71(45 \%)$ & $38(37 \%)$ & $109(42 \%)$ \\
\hline $2000 / 5$ & $108(39 \%)$ & $105(45 \%)$ & $213(42 \%)$ & $62(39 \%)$ & $45(43 \%)$ & $107(41 \%)$ \\
\hline $3000 / 10$ & $13(5 \%)$ & $13(6 \%)$ & $26(5 \%)$ & $8(5 \%)$ & $7(7 \%)$ & $15(6 \%)$ \\
\hline Other & $27(10 \%)$ & $24(10 \%)$ & $51(10 \%)$ & $17(11 \%)$ & $14(13 \%)$ & $31(12 \%)$ \\
\hline
\end{tabular}

GI: Gastrointestinal; GYN: Gynecological

A total of 508 patients completed the ESAS at baseline prior to palliative RT. Their median age was 69 years (range 32 94) and their median Karnofsky performance status (KPS) was 60 (range $10-100$ ). The three most common primary cancer sites were lung $(25 \%)$, breast $(25 \%)$ and prostate
(23\%); and there were slightly more males (54\%) than females (46\%). All other demographic information is reported in Table 1. When assessing baseline ESAS scores in all patients, the mean score of the three worst items were tiredness (4.98), pain (4.36) and well-being (4.35). When evaluating 
Table 2. Baseline ESAS Symptoms and Scores

\begin{tabular}{|c|c|c|c|c|c|c|}
\hline \multirow{3}{*}{ ESAS symptom } & \multicolumn{3}{|c|}{ All Patients } & \multicolumn{3}{|c|}{ Sub-Analysis } \\
\hline & \multicolumn{2}{|c|}{ Mean Score } & \multirow{2}{*}{ P-value } & \multicolumn{2}{|c|}{ Mean Score } & \multirow{2}{*}{ P-value } \\
\hline & Male & Female & & Male & Female & \\
\hline Pain & 4.3 & 4.4 & 0.68 & 4.7 & 4.1 & 0.12 \\
\hline Tiredness & 4.7 & 5.3 & $0.0422 *$ & 4.9 & 5.5 & 0.15 \\
\hline Nausea & 1.3 & 1.8 & $0.0249 *$ & 1.5 & 1.4 & 0.81 \\
\hline Depression & 2.3 & 2.8 & $0.0394 *$ & 2.5 & 2.8 & 0.25 \\
\hline Anxiety & 3.0 & 3.6 & $0.0485^{*}$ & 3.2 & 3.5 & 0.47 \\
\hline Drowsiness & 3.5 & 3.7 & 0.35 & 3.6 & 4.3 & 0.07 \\
\hline Appetite Loss & 3.9 & 4.4 & 0.10 & 4.2 & 4.7 & 0.26 \\
\hline Well-Being & 4.2 & 4.6 & 0.10 & 4.2 & 4.6 & 0.30 \\
\hline Breathlessness & 1.9 & 2.6 & $0.0153 *$ & 2.2 & 2.5 & 0.69 \\
\hline
\end{tabular}

* Females were significantly worse than males.

gender differences in all ESAS items, tiredness $(\mathrm{P}=0.0422)$, nausea $(\mathrm{P}=0.0249)$, depression $(\mathrm{P}=0.0394)$, anxiety $(\mathrm{P}=$ $0.0485)$ and breathlessness $(P=0.0135)$ were significantly worse in females than males. All other baseline ESAS scores can be found in Table 2 .

At follow-up, all items with the exception of dyspnoea were significantly worse for females at some point during the follow-up period. The two most frequently occurring items that showed a significant worsening for females during follow-up were appetite loss at weeks 2, 11, and 12 and nausea at weeks 2,4 , and 6 . At no point did males have significantly worse scores than females throughout the follow-up period.

\section{Sub-analysis excluding patients with gender-specific prima-} ries

A total of 262 patients were included in the subgroup analysis of gender-neutral primaries. The median age was 68 years (range 32 - 89) and the median KPS was 60 (30 - 90). Again there were slightly more males $(60 \%)$ than females $(40 \%)$ but both genders shared very similar demographic information. The most common primary cancer sites were lung $(49 \%)$, unknown $(13 \%)$, multiple myeloma $(11 \%)$ and colorectal (10\%). All other demographic information can be found in Table 1. When assessing baseline ESAS score within this sub-group, the mean score of the three worst items were tiredness (5.11), pain (4.42) and appetite loss (4.38). When evaluating gender differences, there were no significant differences in all ESAS scores at baseline. All other baseline ESAS scores can be found in Table 2 .

At follow-up, all items with the exception of nausea, de- pression and breathlessness were significantly worse in females at some point during the follow-up period. However, as seen in Table 3, the number of items that were significantly worse in females during follow-up dropped to 8 from 15 when compared to the analysis that included all patients. The two most frequently occurring items that showed a significant worsening for females during the follow-up were tiredness at weeks 2 and 13, and drowsiness at weeks 1 and 2. At no point did males have significantly worse score than females throughout the follow-up period.

\section{Brief Pain Inventory}

\section{All patients}

A total of 392 patients completed the BPI at baseline. Their median age was 68 years (range $30-91$ ) and the median KPS was 70 (range 30 - 90). There were more males (60\%) than females $(40 \%)$, however the demographic variables were comparable between both genders at baseline. The most common primary cancer sites were lung $(27 \%)$, breast $(25 \%)$ and prostate $(25 \%)$. All other demographic information is displayed in Table 4. The three items that pain interfered with the most were normal work (6.86), general activity (6.66) and overall enjoyment of life (6.60). When analyzed by gender, the only BPI item that was significantly worse in females was walking ability $(\mathrm{P}=0.0247)$. All other BPI items showed no significant difference between genders. Additional baseline BPI information is presented in Table 5.

At follow-up, all BPI items were significantly worse in females at some point during the follow-up with the excep- 
Table 3. Comparison Male and Female ESAS Item Results During Follow-up After Palliative RT for Bone Metastases

\begin{tabular}{|c|c|c|c|c|c|c|c|c|c|c|c|c|c|c|c|c|}
\hline Weeks & 1 & 2 & 3 & 4 & 5 & 6 & 7 & 8 & 9 & 10 & 11 & 12 & 13 & 14 & 15 & 16 \\
\hline \multicolumn{17}{|l|}{ All Patients } \\
\hline Male & 88 & 109 & 64 & 92 & 55 & 23 & 11 & 47 & 42 & 24 & 19 & 43 & 28 & 19 & 10 & 7 \\
\hline Female & 71 & 94 & 82 & 63 & 59 & 28 & 21 & 52 & 43 & 27 & 16 & 45 & 45 & 17 & 11 & 5 \\
\hline Pain & & & * & & * & & & & & & & & & & & \\
\hline Tiredness & & * & & & & & & & & & & & & & & \\
\hline Nausea & & $*$ & & $*$ & & $*$ & & & & & & & & & & \\
\hline Depression & & & & & & & & & $*$ & & * & & & & & \\
\hline Anxiety & & & & & & & & & & & & & & $*$ & & \\
\hline Drowsiness & & $*$ & & & & & & & $*$ & & & & & & & \\
\hline Appetite Loss & & * & & & & & & & & & $*$ & $*$ & & & & \\
\hline Well-Being & & & & & & & & & * & & & & & & & \\
\hline \multicolumn{17}{|l|}{ Dyspnoea } \\
\hline \multicolumn{17}{|l|}{ Sub-Analysis } \\
\hline Male & 43 & 59 & 42 & 47 & 23 & 13 & 8 & 22 & 24 & 13 & 13 & 27 & 12 & 10 & 7 & 1 \\
\hline Female & 29 & 33 & 29 & 27 & 18 & 8 & 6 & 18 & 17 & 5 & 7 & 12 & 13 & 7 & 4 & 3 \\
\hline \multicolumn{2}{|l|}{ Pain } & & $*$ & & & & & & & & & & & & & \\
\hline \multicolumn{2}{|l|}{ Tiredness } & $*$ & & & & & & & & & & & $*$ & & & \\
\hline \multicolumn{17}{|l|}{ Nausea } \\
\hline \multicolumn{17}{|l|}{ Depression } \\
\hline \multicolumn{2}{|l|}{ Anxiety } & & & & & & & & & & & & & $*$ & & \\
\hline Drowsiness & * & $*$ & & & & & & & & & & & & & & \\
\hline \multicolumn{2}{|l|}{ Appetite Loss } & & & & & & & & & & * & & & & & \\
\hline \multicolumn{2}{|l|}{ Well-Being } & & & & & & & & $*$ & & & & & & & \\
\hline Dyspnoea & & & & & & & & & & & & & & & & \\
\hline
\end{tabular}

* Statistically significant difference between genders $(P<0.05)$

tion of mood. At no point during the follow-up did males experience worse symptoms than females. The most common items that pain had significantly interfered with at follow-up in females were relationships with other people at weeks 4, 8 , and 10; general activity at weeks 5 and 9 ; normal work at weeks 4 and 10; and sleep problems at weeks 8 and 10. All other follow-up information can be found in Table 6 .
Sub-analysis excluding gender-specific cancers

A total of 191 patients were included in the sub-analysis of patients with non gender-specific primaries. The median age was 67 years (range 57 - 74) and the median KPS was 70 (range 40 - 90). There were more males $(65 \%)$ than females (35\%), however demographic variables were compa- 
Table 4. Baseline BPI Cohort Demographics

\begin{tabular}{|c|c|c|c|c|c|c|}
\hline & \multicolumn{4}{|c|}{ All Patients } & \multicolumn{2}{|c|}{ Sub-Analysis } \\
\hline & $\mathbf{M}$ & $\mathbf{F}$ & Overall & M & $\mathbf{F}$ & Overall \\
\hline $\mathrm{N}$ & 227 & 165 & 392 & 126 & 67 & 193 \\
\hline$\%$ & $58 \%$ & $42 \%$ & $100 \%$ & $65 \%$ & $35 \%$ & $100 \%$ \\
\hline \multicolumn{7}{|l|}{ Age } \\
\hline Median (years) & 70 & 61 & 68 & 67 & 66 & 67 \\
\hline Range & $30-91$ & $31-89$ & $30-91$ & $33-86$ & $40-85$ & $33-86$ \\
\hline \multicolumn{7}{|l|}{ KPS } \\
\hline Median & 70 & 70 & 70 & 70 & 70 & 70 \\
\hline Range & $30-90$ & $30-90$ & $30-90$ & $40-90$ & $40-90$ & $40-90$ \\
\hline \multicolumn{7}{|c|}{ Primary Cancer Site (N; \%) } \\
\hline Lung & $68(30 \%)$ & $36(22 \%)$ & $104(27 \%)$ & $68(54 \%)$ & $36(54 \%)$ & $104(54 \%)$ \\
\hline Breast & $2(1 \%)$ & $96(58 \%)$ & $98(25 \%)$ & --- & --- & --- \\
\hline Prostate & $98(43 \%)$ & --- & $98(25 \%)$ & --- & --- & --- \\
\hline Renal Cell & $17(7 \%)$ & $5(3 \%)$ & $22(6 \%)$ & $17(14 \%)$ & $5(8 \%)$ & $22(11 \%)$ \\
\hline Colorectal & $15(7 \%)$ & $7(4 \%)$ & $22(6 \%)$ & $15(12 \%)$ & $7(10 \%)$ & $22(11 \%)$ \\
\hline Unknown & $9(4 \%)$ & $9(6 \%)$ & $18(5 \%)$ & $9(7 \%)$ & $9(13 \%)$ & $18(9 \%)$ \\
\hline Bladder & $7(3 \%)$ & $5(3 \%)$ & $12(3 \%)$ & $7(6 \%)$ & $5(7 \%)$ & $12(6 \%)$ \\
\hline Other GI & $5(2 \%)$ & $3(2 \%)$ & $8(2 \%)$ & $5(4 \%)$ & $3(4 \%)$ & $8(4 \%)$ \\
\hline GYN & --- & $2(1 \%)$ & $2(1 \%)$ & --- & --- & --- \\
\hline Others & $6(3 \%)$ & $2(1 \%)$ & $8(2 \%)$ & $5(4 \%)$ & $2(3 \%)$ & $7(4 \%)$ \\
\hline
\end{tabular}

GI: Gastrointestinal; GYN: Gynecological

rable in both groups. The most common cancer sites were lung $(54 \%)$, renal cell (11\%) and colorectal (11\%). All other demographic variables are presented in Table 4 . The three items that pain interfered with the most were normal work (7.35), general activity (7.02) and enjoyment of life (6.95). When analyzed by gender, the same baseline BPI item found in all patients (walking ability) was still significantly worse in females $(\mathrm{P}=0.0075)$. All other BPI items showed no significant difference between genders. All other baseline BPI information can be found in Table 5 .

At follow-up, several of the associations in the overall analysis between BPI items and females were no longer significant. The only BPI items that were significantly worse in females were normal work, relationships with others and sleep problems at week 8 , and walking ability at week 5 . The number of significant items dropped to 4 from 11 when compared to all patients that were analyzed. All other follow-up information can be found in Table 6 .

\section{Discussion}

Despite several studies that have assessed gender's influence on the prevalence and severity of common cancer symptoms, there is still no consensus regarding the role and extent gender may play $[3,32]$. Patients with cancer can experience similar levels of anxiety and depression as the general population and epidemiological studies have consistently report- 
Table 5. Baseline BPI Items and Scores

\begin{tabular}{|c|c|c|c|c|c|c|}
\hline \multirow{3}{*}{ BPI Items } & \multicolumn{3}{|c|}{ All Patients } & \multicolumn{3}{|c|}{ Sub-Analysis } \\
\hline & \multicolumn{2}{|c|}{ Mean Score } & \multirow{2}{*}{ P-value } & \multicolumn{2}{|c|}{ Mean Score } & \multirow{2}{*}{ P-value } \\
\hline & Male & Female & & Male & Female & \\
\hline Worst Pain & 7.1 & 7.8 & No data & 7.2 & 8.2 & No data \\
\hline Average Pain & 4.9 & 5.2 & No data & 5.0 & 5.3 & No data \\
\hline Current Pain & 3.5 & 4.0 & No data & 4.0 & 4.5 & No data \\
\hline General Activity & 6.5 & 6.9 & 0.27 & 6.7 & 7.6 & 0.10 \\
\hline Mood & 4.9 & 5.4 & 0.16 & 5.0 & 5.6 & 0.31 \\
\hline Walking Ability & 6.1 & 6.3 & $0.0247 *$ & 5.6 & 7.0 & $0.0075^{*}$ \\
\hline Normal Work & 6.7 & 7.1 & 0.52 & 7.0 & 8.0 & 0.34 \\
\hline Relationship & 3.2 & 3.7 & 0.22 & 3.9 & 4.2 & 0.65 \\
\hline Sleeping & 4.8 & 4.9 & 0.78 & 4.8 & 5.7 & 0.14 \\
\hline Enjoyment of Life & 6.6 & 6.6 & 0.81 & 6.7 & 7.3 & 0.27 \\
\hline
\end{tabular}

* Females were significantly worse than males.

ed a higher incidence of depression and anxiety among females [33, 34]. Reviews and meta-analyses of the published literature however, have reported that the results of studies that have analyzed depression and anxiety between genders in cancer patients are confounded by differences in age, tumor type and prognosis; and that these gender differences may not be seen in this population $[4,23,35]$. Certain tumor types for example, have long been linked to higher frequencies of depression and anxiety. With respect to depression, these include pancreatic, head and neck, breast and lung cancers $[4,5,9,36-40]$. Tumor types that have been associated with increased prevalence of anxiety include pancreatic, thyroid, breast and gynecological cancers $[1,7,41]$. Some authors have postulated that pathophysiological effects of these tumors, particularly in their differential expression of enzymes, neurotransmitters, hormones and cytokines could create paraneoplastic syndromes that elevate levels of depression and anxiety $[3,5,38,39]$. Different chemotherapy and hormone therapy treatments, such as tamoxifen, as well as the use of steroids have also been linked to elevated levels of depression and anxiety in cancer patients $[6,10,25,37$, $39,40,42,43]$. Therefore tumor type and their respective treatments may play an important role in the severity and prevalence of anxiety and depression; and the inclusion of gender-specific tumors, such as breast cancer, may artificially increase the perceived rates of anxiety and/or depression among females in the cancer population. Our study findings certainly demonstrated this when upon exclusion of gender- specific primaries, the severity of anxiety and depression were no longer found to be significantly greater in females. Conversely, prostate cancer patients have often been reported to experience lower rates of depression and anxiety; and men in general have been found to under-report their symptoms $[1,9,27,44]$. This could have also influenced the results of the sub-analysis. Other factors that may partially explain our results are recent findings that suggest the gender gap with respect to depression in the general population appears to be narrowing as gender roles become more similar and less traditional; and that perceived gender differences may not appear in the cancer population because the stressors and emotional burden that accompany the disease possibly negate these differences $[21,25,33]$.

In addition to the anxiety and depression, the other symptoms that were evaluated by the ESAS and were found not to vary as a function of gender after the sub-analysis were nausea, tiredness, and dyspnoea. Less research had been devoted to the gender related differences of these symptoms and the majority of such studies have analyzed this relationship in large heterogeneous cancer populations where only the prevalence of these symptoms has been captured. With respect to nausea, two large studies with over 1500 patients each with various tumor types and stages found a high prevalence of nausea in the female population. However both of these studies included gender-specific primaries and upon analysis of symptoms by cancer site, a high prevalence of nausea was found in gynecological and breast cancer patients [17, 
Table 6. BPI Follow-up Results After Palliative RT for Bone Metastases

\begin{tabular}{|c|c|c|c|c|c|c|c|c|c|c|c|c|c|c|}
\hline Weeks & 3 & 4 & 5 & 6 & 7 & 8 & 9 & 10 & 11 & 12 & 13 & 14 & 15 & 16 \\
\hline \multicolumn{15}{|l|}{ All Patients } \\
\hline Male & 41 & 79 & 24 & 14 & 21 & 51 & 34 & 12 & 16 & 39 & 32 & 15 & 17 & 17 \\
\hline Female & 23 & 61 & 27 & 6 & 19 & 35 & 20 & 6 & 23 & 20 & 13 & 11 & 13 & 15 \\
\hline General Activity & & & $*$ & & & & $*$ & & & & & & & \\
\hline \multicolumn{15}{|l|}{ Mood } \\
\hline Walking Ability & & & $*$ & & & & & & & & & & & \\
\hline Normal Work & & $*$ & & & & & & $*$ & & & & & & \\
\hline Relationship & & $*$ & & & & $*$ & & $*$ & & & & & & \\
\hline Sleeping & & & & & & $*$ & & $*$ & & & & & & \\
\hline Enjoyment of Life & & & & & & & $*$ & & & & & & & \\
\hline \multicolumn{15}{|l|}{ Sub-Analysis } \\
\hline \multirow[t]{2}{*}{ Male } & 20 & 37 & 16 & 5 & 10 & 17 & 21 & 6 & 5 & 15 & 19 & 7 & 4 & 7 \\
\hline & 11 & 24 & 12 & 1 & 7 & 15 & 9 & 1 & 6 & 7 & 8 & 4 & 3 & 6 \\
\hline \multicolumn{15}{|l|}{ General Activity } \\
\hline \multicolumn{15}{|l|}{ Mood } \\
\hline Walking Ability & & & $*$ & & & & & & & & & & & \\
\hline Normal Work & & & & & & $*$ & & & & & & & & \\
\hline Relationship & & & & & & $*$ & & & & & & & & \\
\hline Sleeping & & & & & & $*$ & & & & & & & & \\
\hline Enjoyment of Life & & & & & & & & & & & & & & \\
\hline
\end{tabular}

* Statistically significant difference between genders $(P<0.05)$

$18]$. Both of these studies commented that the significantly greater prevalence of nausea in women could very well be attributed to their primary cancer sites or the highly emetogenic chemotherapy regimens $[10,17,18]$.

In the advanced cancer setting, four studies with patient populations ranging from $325-1358$ patients each evaluated nausea and also found it was significantly greater in females $[2,3,10,16]$. However three of the studies found that with analysis of nausea and cancer site, gastrointestinal and breast cancers were significantly associated with patients' experience of nausea and therefore this could have had an impact on the gender findings $[3,10,16]$. Only the study by Walsh et al. [2] still observed a gender difference in females' experience of nausea when controlling for gender-specific primaries, however this study only collected the prevalence of spe- cific symptoms rather than capturing severity or frequency. Apart from nausea, tiredness or fatigue is one of the most frequent and persistent symptoms of cancer and in the advanced cancer setting it has been reported to be present in as many as $89 \%$ of patients $[24,45]$. It has been correlated with high levels of psychological morbidity $[45,46]$ in young and early stage cancer patients, but has been shown to be better correlated with worsening physical symptoms such as pain and dyspnoea in the advanced cancer setting [24]. In a review by Miaskowski et al. [42] that analyzed fatigue in cancer patients, studies that reported greater severity in female patients once again used heterogeneous populations in their analyses. In two unpublished studies by Miaskowski et al. [42], one of which analyzed gender differences in fatigue in 198 advanced cancer patients with bone metastases; as 
well as in two other studies of 95 and 1358 advanced cancer patients respectively, no gender differences were found $[10$, 24]. In addition, several studies that have only analyzed the lung cancer population have also reported no gender differences with respect to fatigue [19, 42, 47]. Of interest, one study published by Engel and colleagues [40] evaluated fatigue as well as other QoL parameters in 988 breast cancer patients and compared them to 327 rectal cancer patients. They found the breast cancer patients reported significantly higher rates of fatigue when compared to both the female and male rectal cancer patients, suggesting that breast cancer patients may artificially inflate gender related differences. This same study also reported that breast cancer patients, particularly those treated with adjuvant therapy, reported more dyspnoea than the rectal cancer patients.

Dyspnoea is reportedly present in about $11-28 \%$ of cancer patients and as expected it is found significantly more often in lung cancer patients [13, 16-18, 48]. Very few studies have included dyspnoea as a variable in gender related studies, however of those that did, no significant differences have been reported between genders $[2,10,13,16,18]$.

With regards to the patients that had completed the BPI, one functional symptom was significant in both the overall and the non-gender-specific sub-analysis. Females reported that pain had more interference on their walking ability than males, despite both groups reporting similar current, average and worst pain scores. Most studies do not report a gender difference with respect to functional symptoms; however none of these studies have evaluated this outcome in an advanced cancer population of patients with bone metastases $[17,25,28]$. Patients with painful sites in the lower extremities requiring radiation treatment have been reported to experience greater functional inference [49]; however there was no difference between the genders regarding lower extremity treatment sites to explain the phenomenon. After palliative RT treatment, the only other time females experienced significantly more interference in their walking ability was at week 5 and it was not seen beyond this time point.

Briefly, with respect to follow-ups in both the ESAS and BPI patients, the number of significant gender differences upon exclusion of gender-specific primaries dropped by $47 \%$ and $64 \%$ respectively. There are no symptoms or functional interference items that were consistently worse among females in the sub-analysis. The greatest number of follow-ups for ESAS was at week 2 ( $40 \%$ of total accrued) and at week 4 for BPI patients (36\% of total accrued). Therefore the interpretation of any significant results with respect to gender differences, especially beyond week 4 , may not be representative or particularly meaningful. The only symptoms which were significantly greater in females at more than one time period were tiredness and drowsiness at weeks 1, 2, and 13 .

Existing studies that have evaluated gender differences in heterogeneous cancer populations that include breast, prostate and gynecological cancers should be appraised critically, especially when they have not accessed the effects tumor type, cancer stage or other demographic factors may have on the severity and frequency of symptoms in the population. A clear-cut example of the potential influence gender-specific primaries may have on study outcomes can also be seen in the study by Engel et al. [40]. In a comparison of breast and rectal cancer patients, breast cancer patients were found to have significantly poorer scores on over half of the QoL items, including emotional functioning, fatigue, pain and insomnia even when controlling for adjuvant treatment, gender and age. The authors reported that this might be explained by the public's perception of breast cancer and women's fear of developing the disease due to the heightened publicity it receives when compared to other cancers. Since breast cancer has the highest reported incidence of female cancers [50], it can easily impact gender studies and artificially inflate the severity and prevalence of symptoms in females. Therefore one should not assume that symptom severity and frequency in patients with gender-specific primaries are generalizable to the entire cancer population.

The limitations of this study are primarily centered on the type of cancer population assessed. In order to keep a more homogenous population, the 900 patients all had bone metastases and received palliative RT to their painful bony sites. The results of this study therefore may not be representative of patients with early-stage cancer or patients with other metastases. In addition, other limitations of this study include those methodological concerns that are typically encountered in studies of patients with advanced cancer. There was a high attrition rate presumably due to patients suffering from declining performance status, competing health concerns or death. There was likely also greater relative accrual of patients with good performance status than patients with advanced cancer in general. Finally, although the size of this exploratory study is large at 900 patients, given the similarly high number of statistical comparisons needed to properly explore the main study question, more rigorous corrections for multiple comparisons were not performed as they could have easily masked the hypothesis generating findings found herein despite the large study cohort.

Overall, this study clearly demonstrates the importance of controlling for the influence of gender-specific primaries when investigating the effect of gender on the prevalence and severity of symptoms among patients with advanced cancer. Future studies should always take into account gender-specific primaries through multivariate analyses or by sub-analyses when analyzing gender relationships in the cancer population.

\section{Acknowledgements}

This study was supported by the Michael and Karyn Goldstein Cancer Research Fund and we thank Mrs. Stacy Yuen 
and Ms. Kristina Facchini for their assistance.

\section{Conflicts of Interest}

None

\section{References}

1. Parker PA, Baile WF, de Moor C, Cohen L. Psychosocial and demographic predictors of quality of life in a large sample of cancer patients. Psychooncology 2003;12(2):183-193.

2. Walsh D, Donnelly S, Rybicki L. The symptoms of advanced cancer: relationship to age, gender, and performance status in 1,000 patients. Support Care Cancer 2000;8(3):175-179.

3. Mercadante S, Casuccio A, Pumo S, Fulfaro F. Factors influencing the opioid response in advanced cancer patients with pain followed at home: the effects of age and gender. Support Care Cancer 2000;8(2):123-130.

4. van't Spijker A, Trijsburg RW, Duivenvoorden HJ. Psychological sequelae of cancer diagnosis: a meta-analytical review of 58 studies after 1980. Psychosom Med 1997;59(3):280-293.

5. Brintzenhofe-Szoc KM, Levin TT, Li Y, Kissane DW, Zabora JR. Mixed anxiety/depression symptoms in a large cancer cohort: prevalence by cancer type. Psychosomatics 2009;50(4):383-391.

6. Akechi T, Okuyama T, Sugawara Y, Nakano T, Shima Y, Uchitomi Y. Major depression, adjustment disorders, and post-traumatic stress disorder in terminally ill cancer patients: associated and predictive factors. J Clin Oncol 2004;22(10):1957-1965.

7. Zabora J, BrintzenhofeSzoc K, Curbow B, Hooker C, Piantadosi S. The prevalence of psychological distress by cancer site. Psychooncology 2001;10(1):19-28.

8. Hann D, Baker F, Denniston M, Gesme D, Reding D, Flynn T, Kennedy J, et al. The influence of social support on depressive symptoms in cancer patients: age and gender differences. J Psychosom Res 2002;52(5):279283.

9. Carlson LE, Angen M, Cullum J, Goodey E, Koopmans J, Lamont L, MacRae JH, et al. High levels of untreated distress and fatigue in cancer patients. Br J Cancer 2004;90(12):2297-2304.

10. Cheung WY, Le LW, Gagliese L, Zimmermann C. Age and gender differences in symptom intensity and symptom clusters among patients with metastatic cancer. Support Care Cancer 2011;19(3):417-423.

11. Zimmermann C, Burman D, Swami N, Krzyzanowska MK, Leighl N, Moore M, Rodin G, et al. Determinants of quality of life in patients with advanced cancer. Support Care Cancer 2011;19(5):621-629.

12. Jacobsen PB, Donovan KA, Trask PC, Fleishman SB, Zabora J, Baker F, Holland JC. Screening for psychologic distress in ambulatory cancer patients. Cancer 2005;103(7):1494-1502.

13. Portenoy RK, Thaler HT, Kornblith AB, Lepore JM, Friedlander-Klar H, Coyle N, Smart-Curley T, et al. Symptom prevalence, characteristics and distress in a cancer population. Qual Life Res 1994;3(3):183-189.

14. Rispoli A, Pavone I, Bongini A, Di Loro F, Ponchietti R, Rizzo M. Genitourinary cancer: psychological assessment and gender differences. Urol Int 2005;74(3):246249.

15. Lehto US, Ojanen M, Kellokumpu-Lehtinen P. Predictors of quality of life in newly diagnosed melanoma and breast cancer patients. Ann Oncol 2005;16(5):805-816.

16. Mercadante S, Casuccio A, Fulfaro F. The course of symptom frequency and intensity in advanced cancer patients followed at home. J Pain Symptom Manage 2000;20(2):104-112.

17. Vainio A, Auvinen A. Prevalence of symptoms among patients with advanced cancer: an international collaborative study. Symptom Prevalence Group. J Pain Symptom Manage 1996;12(1):3-10.

18. Grond S, Zech D, Diefenbach C, Bischoff A. Prevalence and pattern of symptoms in patients with cancer pain: a prospective evaluation of 1635 cancer patients referred to a pain clinic. J Pain Symptom Manage 1994;9(6):372382.

19. Gift AG, Stommel M, Jablonski A, Given W. A cluster of symptoms over time in patients with lung cancer. Nurs Res 2003;52(6):393-400.

20. Hopwood P, Stephens RJ. Depression in patients with lung cancer: prevalence and risk factors derived from quality-of-life data. J Clin Oncol 2000;18(4):893-903.

21. Miller S, Lo C, Gagliese L, Hales S, Rydall A, Zimmermann $\mathrm{C}, \mathrm{Li}$ M, et al. Patterns of depression in cancer patients: an indirect test of gender-specific vulnerabilities to depression. Soc Psychiatry Psychiatr Epidemiol 2010.

22. Ryan H, Schofield P, Cockburn J, Butow P, Tattersall M, Turner J, Girgis A, et al. How to recognize and manage psychological distress in cancer patients. Eur J Cancer Care (Engl) 2005;14(1):7-15.

23. Pirl WF. Evidence report on the occurrence, assessment, and treatment of depression in cancer patients. J Natl Cancer Inst Monogr 2004;(32):32-39.

24. Stone P, Hardy J, Broadley K, Tookman AJ, Kurowska A, A'Hern R. Fatigue in advanced cancer: a prospective controlled cross-sectional study. Br J Cancer 1999;79(910):1479-1486.

25. Turk DC, Okifuji A. Does sex make a difference in the prescription of treatments and the adaptation to chronic pain by cancer and non-cancer patients? Pain 
1999;82(2):139-148.

26. Mercadante S, Dardanoni G, Salvaggio L, Armata MG, Agnello A. Monitoring of opioid therapy in advanced cancer pain patients. J Pain Symptom Manage 1997;13(4):204-212.

27. Volkers N. In coping with cancer, gender matters. J Natl Cancer Inst 1999;91(20):1712-1714.

28. Greimel ER, Padilla GV, Grant MM. Gender differences in outcomes among patients with cancer. Psychooncology 1998;7(3):197-206.

29. Bruera E, Kuehn N, Miller MJ, Selmser P, Macmillan K. The Edmonton Symptom Assessment System (ESAS): a simple method for the assessment of palliative care patients. J Palliat Care 1991;7(2):6-9.

30. Chang VT, Hwang SS, Feuerman M. Validation of the Edmonton Symptom Assessment Scale. Cancer 2000;88(9):2164-2171.

31. Cleeland CS, Gonin R, Hatfield AK, Edmonson JH, Blum RH, Stewart JA, Pandya KJ. Pain and its treatment in outpatients with metastatic cancer. $\mathrm{N}$ Engl $\mathrm{J}$ Med 1994;330(9):592-596.

32. Pikler VI, Brown C. Cancer patients' and partners' psychological distress and quality of life: influence of gender role. J Psychosoc Oncol 2010;28(1):43-60.

33. Seedat S, Scott KM, Angermeyer MC, Berglund P, Bromet EJ, Brugha TS, Demyttenaere K, et al. Cross-national associations between gender and mental disorders in the World Health Organization World Mental Health Surveys. Arch Gen Psychiatry 2009;66(7):785-795.

34. Vesga-Lopez O, Schneier FR, Wang S, Heimberg RG, Liu SM, Hasin DS, Blanco C. Gender differences in generalized anxiety disorder: results from the National Epidemiologic Survey on Alcohol and Related Conditions (NESARC). J Clin Psychiatry 2008;69(10):16061616.

35. Stark DP, House A. Anxiety in cancer patients. Br J Cancer 2000;83(10):1261-1267.

36. Holland JC, Korzun AH, Tross S, Silberfarb P, Perry M, Comis R, Oster M. Comparative psychological disturbance in patients with pancreatic and gastric cancer. Am J Psychiatry 1986;143(8):982-986.

37. Ciaramella A, Poli P. Assessment of depression among cancer patients: the role of pain, cancer type and treatment. Psychooncology 2001;10(2):156-165.
38. Carney CP, Jones L, Woolson RF, Noyes R, Jr., Doebbeling BN. Relationship between depression and pancreatic cancer in the general population. Psychosom Med 2003;65(5):884-888.

39. Massie MJ. Prevalence of depression in patients with cancer. J Natl Cancer Inst Monogr 2004;(32):57-71.

40. Engel J, Kerr J, Schlesinger-Raab A, Eckel R, Sauer H, Holzel D. Comparison of breast and rectal cancer patients' quality of life: results of a four year prospective field study. Eur J Cancer Care (Engl) 2003;12(3):215223.

41. Miller K, Massie MJ. Depression and anxiety. Cancer J 2006;12(5):388-397.

42. Miaskowski C. Gender differences in pain, fatigue, and depression in patients with cancer. J Natl Cancer Inst Monogr 2004;(32):139-143.

43. Kornblith AB, Herr HW, Ofman US, Scher HI, Holland JC. Quality of life of patients with prostate cancer and their spouses. The value of a data base in clinical care. Cancer 1994;73(11):2791-2802.

44. Kiss A, Meryn S. Effect of sex and gender on psychosocial aspects of prostate and breast cancer. BMJ 2001;323(7320):1055-1058.

45. Valentine AD, Meyers CA. Cognitive and mood disturbance as causes and symptoms of fatigue in cancer patients. Cancer 2001;92(6 Suppl):1694-1698.

46. Hann D, Winter K, Jacobsen P. Measurement of depressive symptoms in cancer patients: evaluation of the Center for Epidemiological Studies Depression Scale (CESD). J Psychosom Res 1999;46(5):437-443.

47. Hoffman AJ, Given BA, von Eye A, Gift AG, Given CW. Relationships among pain, fatigue, insomnia, and gender in persons with lung cancer. Oncol Nurs Forum 2007;34(4):785-792.

48. Brescia FJ, Adler D, Gray G, Ryan MA, Cimino J, Mamtani R. Hospitalized advanced cancer patients: a profile. J Pain Symptom Manage 1990;5(4):221-227.

49. Wu JS, Beaton D, Smith PM, Hagen NA. Patterns of pain and interference in patients with painful bone metastases: a brief pain inventory validation study. J Pain Symptom Manage 2010;39(2):230-240.

50. Canadian Cancer Society's Steering Committee. Canadian cancer statistics 2010. Canadian Cancer Society, ed. Toronto: Canadian Cancer Society, 2010. 